10 years ESJ

Special edition

\title{
Preface: GROWTH OF BUSINESS AND SOCIETY IN POST CRISIS PERIOD
}

\author{
Prof. Dr. Vasilika Kume \\ Faculty of Economy, Tirana University, Albania
}

Doi: $10.19044 / \mathrm{esj} .2021 . v 17 \mathrm{n} 11 \mathrm{p} 1$

Submitted: 18 September 2020

Accepted: 22 January 2021

Published: 02 April 2021
Copyright 2021 Author(s)

Under Creative Commons BY-NC-ND

4.0 OPEN ACCESS

Cite As:

Kume V. (2021). Preface: GROWTH OF BUSINESS AND SOCIETY IN POST CRISIS PERIOD. European Scientific Journal, ESJ, 17(11), 1.

https://doi.org/10.19044/esj.2021.v17n11p1

Coronavirus is pushing economies towards economic recession, at a time when all parameters and trends were positive. Social distancing is turning into economic distancing. Leading economists are proposing "extreme reforms" to fight the economic catastrophe that could be caused by the COVID-19 pandemic.

There is a consensus among analysts and experts in various fields that after the end of the COVID-19 pandemic, "nothing will be the same". It will be a "new reality", with many changes in lifestyle and way of doing business. However, one of the expectations is changes in customer behavior.

"Moving rapidly across borders, along the major arteries of the global economy, the spread of the coronavirus has benefited from the interconnections and weaknesses of globalization, being catapulted from a global health crisis to a global economic shock," said the UNCTAD SecretaryGeneral, Mukhisa Kituyi.

"Globalization", which is regarded as one of the causes of this economic collapse, is being reflected to be replaced with "glocalization", as a tendency to preserve the uniqueness of national and local values. Of course, this trend will greatly affect all the economies of different countries of the world, especially in developing countries which are highly exposed to globalization.

In the wake of 'a war' and maximum health commitments, analysis and judgment of the expected post-coronavirus economic scenarios cannot be 
considered "luxury and premature". Consequently, when the coronavirus curve move towards the end, the curve of its negative effects on the economy will be at its peak, demanding precise measures and policies to be affected as little as possible, economically and financially, and to have strategies of development in the new economic cycle that is expected to begin.

Above all, the commitment of researchers and academics to contribute is a must. This special issue has been motivated by the current state of things. This is a challenging task as it requires considering and combining the many different impacts of the pandemic on our lives. Through this publication, the authors aim to make a modest contribution to the necessary policies and orientations of the economy in the Post-COVID period. Therefore, the focus is to expand the understanding of the ways in which businesses, economies, government, and other institutions will respond to these challenges.

We hope this special issue helps us in alleviating that informational deficiency. 